This article was downloaded by: [Utah State University Libraries]

On: 25 October 2012, At: 09: 17

Publisher: Routledge

Informa Ltd Registered in England and Wales Registered Number: 1072954 Registered

office: Mortimer House, 37-41 Mortimer Street, London W1T 3J H, UK

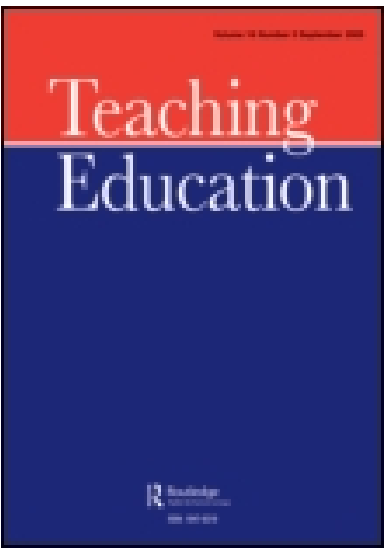

\title{
Teaching Education
}

Publication details, including instructions for authors and subscription information:

http:// www.tandfonline.com/loi/ cted20

\section{Teaching anxieties revealed: pre- service elementary teachers' reflections on their mathematics teaching experiences}

Amy Brown ${ }^{a}$, Arla Westenskow ${ }^{a} \&$ Patricia Moyer-Packenham ${ }^{a}$

a School of Teacher Education and Leadership, Utah State University, Logan, UT, USA

Version of record first published: 25 Oct 2012.

To cite this article: Amy Brown, Arla Westenskow \& Patricia Moyer-Packenham (2012): Teaching anxieties revealed: pre-service elementary teachers' reflections on their mathematics teaching experiences, Teaching Education, 23:4, 365-385

To link to this article: http:// dx.doi.org/ 10.1080/ 10476210.2012.727794

\section{PLEASE SCROLL DOWN FOR ARTICLE}

Full terms and conditions of use: http://www.tandfonline.com/page/terms-andconditions

This article may be used for research, teaching, and private study purposes. Any substantial or systematic reproduction, redistribution, reselling, loan, sub-licensing, systematic supply, or distribution in any form to anyone is expressly forbidden.

The publisher does not give any warranty express or implied or make any representation that the contents will be complete or accurate or up to date. The accuracy of any instructions, formulae, and drug doses should be independently verified with primary sources. The publisher shall not be liable for any loss, actions, claims, proceedings, demand, or costs or damages whatsoever or howsoever caused arising directly or indirectly in connection with or arising out of the use of this material. 


\title{
Teaching anxieties revealed: pre-service elementary teachers' reflections on their mathematics teaching experiences
}

\author{
Amy Brown*, Arla Westenskow and Patricia Moyer-Packenham \\ School of Teacher Education and Leadership, Utah State University, Logan, UT, USA
}

(Received 20 December 2011; final version received 20 August 2012)

\begin{abstract}
Over the last 50 years, there has been ample research dedicated to mathematics anxiety in contexts of teaching and learning. However, there has been less attention focused on pre-service teachers' anxieties about teaching mathematics in classroom settings. This study analyzed pre-service teachers' reflections at the conclusion of an elementary mathematics field experience in order to determine common themes surrounding anxiety-related events based on mathematics practice-teaching experiences. Through qualitative analysis of pre-service teachers' reflections using open and axial coding, three categories and ten themes surrounding elementary pre-service teachers' anxiety-related events based on mathematics practice-teaching experiences emerged. Some of the themes presented were ones that increased pre-service teachers' anxieties for teaching mathematics, whereas other themes reflected aspects of the field experience that decreased anxiety for teaching mathematics. Based on the themes revealed in this study, suggestions for strategies and materials that could be developed for university mathematics methods courses are discussed. Novel perspectives for considering mathematics teaching anxiety, such as locus of control and future time perspective, are shared.
\end{abstract}

Keywords: mathematics anxiety; mathematics teaching anxiety; elementary preservice teachers; mathematics field experiences; mathematics practicum

\section{Introduction}

Little is known about the anxieties pre-service teachers experience during the actual teaching of mathematics in elementary classrooms. For example, are there particular events that contribute to, or reduce, anxiety during mathematics teaching? However, much has been written about pre-service teachers' mathematics anxiety when participating in mathematics content and mathematics methods coursework. Research reveals a variety of factors and prior experiences that contribute to pre-service teachers' mathematics anxiety. The purpose of this research was to focus specifically on pre-service teachers' identification of practicum-based mathematics classroom teaching experiences that contributed to their anxiety, or reduced their anxiety, during the teaching of elementary mathematics. As teacher educators and mentor teachers, the identification of these events would allow us to structure pre-service teachers' practicum experiences to address anxiety-provoking events and promote events that reduce anxiety. This could provide pre-service teachers with a more

*Corresponding author. Email: amy.brown@usu.edu 
positive experience during their practicum teaching of elementary mathematics, and better prepare them for positive and successful mathematics teaching experiences as elementary teachers.

\section{Different types of anxiety: mathematics anxiety}

The term mathematics anxiety is largely credited to the work of Sheila Tobias. In her book Overcoming Math Anxiety (1978), Tobias first described mathematics anxiety as a feeling of sudden death, or something that students felt that they would never be able to overcome. Since then, mathematics anxiety also includes: low self confidence in mathematical abilities, a fear of failing to understand mathematics concepts, negative attitudes towards mathematics, and a dread of mathematics (Bursal \& Paznokas, 2006; Gresham, 2004). Frequently, people experiencing mathematics anxiety also feel helplessness, shame, fear, and physical symptoms such as a nervous stomach, difficulty breathing, and a loss of concentration (Gresham, 2007).

Mathematics anxiety affects learning and causes individuals to perform at lower levels than their capabilities. Research has shown that people with mathematics anxiety are hesitant to perform mathematical tasks in front of their peers, perform poorly in testing and problem-solving situations, avoid mathematical situations and instruction, and develop learned helplessness (Beilock, Gunderson, Ramirez, \& Levine, 2010; Brady \& Bowd, 2005; Gresham, 2007; Trujillo \& Hadfield, 1999; Vinson, 2001). In a meta-analysis of 151 studies, Hembree (1990) found that mathematics anxiety was related to poor performance and avoidance of mathematical situations.

In 1972, the Mathematics Anxiety Rating Scale (MARS) (Richardson \& Suinn) was developed to measure the construct mathematics anxiety. Over the past few decades, numerous studies have implemented the MARS instrument, particularly with pre-service teachers. One such study used pre-service teachers' MARS scores in pre/posttest designs following a methods course, finding that anxiety levels somewhat decreased following the course (Harper \& Daane, 1998). Another study examined pre-service teachers' MARS scores compared to their mathematics efficacy beliefs and found connections between the two constructs (Bursal \& Paznokas, 2006).

Additional studies that have examined mathematics anxiety, specifically with pre-service teachers, reveal concerning results. According to three recent studies, over one-third of pre-service teachers reported characteristics of mathematics anxiety. For example, 38\% of pre-service teachers reported low confidence in their ability to learn mathematics (Dogan-Dunlap, Dunlap, Izquierdo, \& Kosheleva, 2007), 34\% indicated high levels of mathematics anxiety (Cady \& Rearden, 2007), and $39 \%$ indicated that mathematics was their least liked subject (Brady \& Bowd, 2005). These high numbers of reported mathematics anxiety are concerning for mathematics educators charged with preparing pre-service teachers to teach mathematics.

Research on the effects of or changes in pre-service teachers' mathematics anxiety during mathematics methods courses has shown positive findings. When the MARS was implemented in a pre/postdesign within the context of a mathematics methods course, researchers found significant decreases in pre-service teachers' anxiety (Gresham, 2007; Harper \& Daane, 1998; Vinson, Haynes, Brasher, Sloan, \& Gresham, 1997). Other research examining mathematics anxiety during a 
mathematics methods course documented a shift by pre-service teachers from a teacher focus to a student focus, with lower levels of mathematics anxiety (Levine, 1993).

\section{Different types of anxiety: mathematics teaching anxiety}

Concern about the negative effects of mathematics anxiety on performance has led researchers to question whether or not a teachers' mathematics anxiety affects their ability to teach. Beilock et al. (2010) correlated the mathematics achievement of 117 students with 17 teachers' mathematics anxiety ratings at the beginning and the end of a school year. Correlations at the beginning of the year indicated no relationship between students' mathematics achievement and teachers' mathematics anxiety scores, however, at the end of the year, the girls' achievement correlated negatively with their teachers' mathematics anxiety $(r=-.28, p=.022)$, while boys did not $(r=-.04, p=.81)$. This study indicates that girls might be more affected by their teachers' high levels of mathematics anxiety than their male classmates.

However, very little research has been dedicated to examining pre-service teachers' anxiety during the teaching of mathematics, an experience described as mathematics teaching anxiety (MTA) (Peker, 2009). The phrase mathematics anxiety describes an individual's internal lack of mathematics content knowledge or confidence, whereas MTA reflects how an individual gages her/his ability to communicate with and engage children in mathematics interactions (Brown, Westenskow, \& Moyer-Pakenham, 2011). While the areas of mathematics anxiety and MTA have been difficult to isolate from one another in research with pre-service teachers, a Turkish researcher has recently developed such an instrument titled the "Mathematics Teaching Anxiety Scale (MATAS)" (Peker, 2009). Peker used this instrument with pre-service and in-service teachers to investigate MATAS scores between elementary and secondary mathematics teachers, as well as between teachers' different learning styles. The construct of MTA has gained attention and precision in recent studies that separate it from the more general construct of mathematics anxiety. Therefore, this study focused more specifically on pre-service teachers' mathematics anxiety and MTA in the context of field-based mathematics teaching.

\section{Research question}

The literature on mathematics anxiety and MTA demonstrates the interaction between the constructs on the mathematics teaching/learning process for elementary teachers and students. The literature also shows that little research has focused specifically on MTA experiences that occur during practice-teaching experiences. The research in this study had exactly this aim: to examine the anxiety-related events reported by pre-service teachers based on their mathematics practice-teaching experiences in elementary classrooms. The following research question guided this investigation: Are there common themes of anxiety-provoking or anxiety-reducing events among pre-service elementary teachers' that occur during mathematics teaching practica experiences? To answer this question, we examined pre-service teachers' reflections following an elementary mathematics teaching experience to identify common themes surrounding their anxieties, and determine the influence of different practice-teaching events on their anxiety for teaching elementary mathematics. Through this examination, we sought to learn more about the anxiety-provoking 
and anxiety-reducing events that occur during practice teaching so that structured mathematics teaching experiences for reducing pre-service teachers' mathematics teaching anxieties could be developed for mathematics methods coursework.

\section{Methods \\ Participants}

The participants in this study were 55 pre-service elementary teachers enrolled as undergraduates in their senior year of a Bachelor's degree program in elementary education at a public university in the western USA. Consistent with the current teaching population of elementary teachers, the majority of the participants were female, white, and traditional students in terms of age (19-26). The majority of the participants were enrolled in a typical elementary education program that would lead to state certification in grades one through six; some participants had additional emphases in areas such as early childhood or middle grades mathematics.

\section{Methods courses and field placements}

The participants were enrolled in three different sections of a mathematics methods course taught by three different instructors. Two of the course sections were taught at one campus site, and the third section was taught at the second campus site. The three methods course sections used syllabi with common learning objectives and common practicum assignments; all three methods courses implemented the same timeline of 10 weeks in the university classroom followed by five weeks of field placements in public school classrooms.

The pre-service teachers' field placements were coordinated and arranged by a central field experience office within the university, and all pre-service teachers were placed in a K-6 public school classroom with a state certified teacher and were assigned a university supervisor. The field placements existed among several different school districts within the state. During the five-week practicum experience, pre-service teachers attended school for full days (7-8h), and engaged in a variety of experiences such as: working with small groups; managing attendance and assessment records; implementing classroom transitions; and planning and teaching whole-group lessons in several different content areas including mathematics.

\section{Methods course instructors}

The three instructors of the different course sections each had education degrees and years of teaching experience required by the university in order to teach the senior level mathematics methods course. All three instructors had K-8 teaching experience, ranging from 6 to 29 years with an average of 15 years. Additionally, each instructor had prior experience teaching mathematics methods to elementary pre-service teachers; this experience ranged from 4 to 15 years, with an average of 9 years of mathematics methods teaching experience. As previously stated, the three instructors met prior to the initiation of the course to agree on common objectives and assignments between the three course sections. 


\section{Instrument}

The primary instrument used to collect data during this study was a common Lesson Plan and Reflection Assignment. The assignment required pre-service teachers to teach three mathematics lessons in an elementary school during the semester and to write a focused reflection describing their teaching experiences. The format, timeline, and grading rubric for the assignment were designed and agreed upon by all three methods instructors at the start of the semester. The Lesson Plan and Reflection Assignment included six sections: Objectives, Materials, Procedures, Assessment, Analysis of Student Work/Student Work Samples, and Reflection. For the purposes of this study, our analyses focused only on the data gathered in response to the reflection section. The reflection section of the assignment consisted of five questions, which were explained to the pre-service teachers prior to their practicum experience:

(1) How confident did you feel while you were teaching your mathematics lessons?

(2) Were you more comfortable teaching the mathematics lessons or the lessons in one of the other subjects? Please explain WHY?

(3) Describe your best moment when teaching a mathematics lesson. What happened?

(4) Describe your worst moment when teaching a mathematics lesson. What happened?

(5) Explain how your own personal experiences with mathematics influenced your mathematics teaching during the practicum experience.

The five reflection questions were selected based on connections to the literature surrounding mathematics anxiety and mathematics teaching anxiety. Question 1 asked pre-service teachers to describe their confidence while teaching mathematics; confidence is an area related to mathematics anxiety among elementary pre-service teachers (Dogan-Dunlap et al., 2007). Question 2 asked pre-service teachers to compare their comfort levels in teaching mathematics compared to other subject areas, which connects to elementary pre-service teachers with mathematics anxiety reporting mathematics as their least favorite subject (Brady \& Bowd, 2005). Questions 3 and 4 addressed the two extremes within the construct of MTA (Brown et al., 2011; Peker, 2009), where pre-service teachers reflected on both positive and negative moments directly related to their mathematics teaching. Finally, Question 5 asked pre-service teachers to connect their mathematics teaching experiences to past, personal experiences with mathematics; prior research has connected negative previous mathematics experiences to higher levels of mathematics anxiety in elementary preservice teachers (Uusimaki \& Nason, 2004).

\section{Procedures}

At the beginning of the semester, the three instructors explained the course assignment and distributed written materials outlining the requirements. In addition, preservice teachers were told that, at the conclusion of the semester, students would have the option of participating in the research study by sending an electronic copy of the portion of their assignment that contained the reflection questions to their instructor. Throughout the semester, the three mathematics methods courses 
met on-campus for 10 weeks of instruction, followed by a five-week teachingpracticum experience in a K-6 elementary school. While completing the five-week practicum experience, pre-service teachers were required to plan and teach a minimum of three mathematics lessons, although many of them had opportunities to teach more than three mathematics lessons. The pre-service teachers also had teaching requirements in other content areas (e.g. science, language arts, and social studies). At the conclusion of the practicum experience, the pre-service teachers submitted their Lesson Plan and Reflection Assignment to their respective instructors. These assignments were graded and returned to the pre-service teachers. After the semester concluded, instructors emailed the pre-service teachers and asked them to voluntarily submit an electronic copy of the reflection portion of the assignment to be used in the present analysis. Of 62 pre-service teachers enrolled in the three mathematics methods sections, 55 submitted the reflections on their mathematics teaching.

\section{Data analysis}

The following process was used to code the 55 narrative documents created by the pre-service teachers. First, each instructor created a combined file of all of the reflections submitted by the pre-service teachers in her course. This process removed all identifying information from the narratives, and each pre-service teacher was assigned a number, for example, "PT1." Next, three readers independently reviewed the narratives in their entirety, with two of the readers coding $100 \%$ of the data, and one reader coding $36 \%$ of the data. In analyzing the data, the readers agreed to highlight and code pre-service teachers' affective descriptions of events based on mathematics practice-teaching experiences. Key terms and phrases such as the following were highlighted and coded within pre-service teachers' reflections: what they did/did not like; what made them more/less comfortable; descriptions of nervousness/embarrassment; descriptions of frustrations and successes, etc. Both open and axial coding was implemented for the purpose of categorical aggregation (Stake, 1995; Strauss \& Corbin, 1998). The readers used the process of open coding to identify major themes in the pre-service teachers' reflections. Following independent coding, the readers met to determine agreement on the three major categories contained in the reflections. After determining these major categories, the readers returned to the coded data to identify examples that formed the axes, or themes, for each category. Using this process helped to reveal examples and nonexamples for each category.

In some cases, pre-service teachers' descriptions of events were complex and crossed into more than one theme; when this occurred, the three readers came to a consensus and coded the text in the theme that best matched the primary emphasis. Therefore, the pre-service teacher quotes presented in the results sometimes contain elements that represent more than one of the major themes. We also recognized that some of the reflections shared by pre-service teachers about their anxiety-related events during practice mathematics teaching might be characteristic of any content area in the elementary curriculum in general. Therefore, while the participants reflected upon their practice mathematics teaching specifically, some results could be applied to other elementary disciplines. 


\section{Results: major themes}

The results that follow present three major categories of pre-service teachers' experiences during their teaching of elementary mathematics: Adapting to established teaching structures; Preparing for the mathematics classroom; and Recognizing personal attributes for mathematics teaching. Table 1 (Appendix A) documents the number of distinct ideas in pre-service teachers' quotes that were coded within the three categories, and the percent that the category represents within the entire data-set of pre-service teacher quotes. These three categories were established using research regarding internal-external locus of control (Rose \& Medway, 1981; Rotter, 1966). The "Adapting to established teaching structures" category $(N=57 ; 29.1 \%)$ describes pre-service teachers' reflections about the existing classroom environment in which they are placed for practicum teaching (external locus of control). "Preparing for the mathematics classroom" $(N=81 ; 41.3 \%)$ is a category where pre-service teachers are sometimes able to execute control over their mathematics practice-teaching experiences. The category of "Recognizing personal attributes for mathematics teaching" $(N=58$; $29.6 \%$ ) is the category that reveals pre-service teachers' internal locus of control regarding their mathematics practice teaching. Therefore, the three major categories are linear in that they are listed from the most externally focused locus of control to the most internally focused, however, the $10 \mathrm{key}$ themes presented within the three major categories are not listed in any particular order or hierarchy.

Within the three major categories are 10 key themes that emerged from preservice teachers' reflection responses. Table 1 (Appendix A) reveals the number of quotes written by pre-service teachers that were coded for each of the 10 themes, as well as the percent the theme represents within the larger category. Woven throughout the pre-service teachers' responses in each of these themes are experiences that contributed to pre-service teachers' anxieties and others that reduced pre-service teachers' anxiety-related events during mathematics practice-teaching experiences. Figure 1 (Appendix B) presents the three major categories and the 10 major themes that emerged from the pre-service teachers' reflections on their teaching experiences.

Table 1. Number and percent of pre-service teacher quotes per category and theme.

\begin{tabular}{lcc}
\hline Categories and sub-themes & Number of quotes & Percent of the category (\%) \\
\hline Adapting to established teaching structures $(N=57 ; 29.1 \%)$ & \\
Resources & 21 & 36.8 \\
Curricular structure & 9 & 15.8 \\
Classroom management & 13 & 22.8 \\
Supervision & 14 & 24.6 \\
Preparing for the mathematics classroom $(N=81 ; 41.3 \%)$ & 8.6 \\
Observing other teachers & 7 & 25.9 \\
Practice and reflection & 21 & 27.2 \\
Preparation & 22 & 38.3 \\
Children's understanding & 31 & 20.7 \\
Recognizing personal attributes for mathematics teaching $(N=58 ; 29.6 \%)$ & 74.1 \\
Emotional impact & 12 & \\
Previous experiences with mathematics & 43 & \\
\hline
\end{tabular}




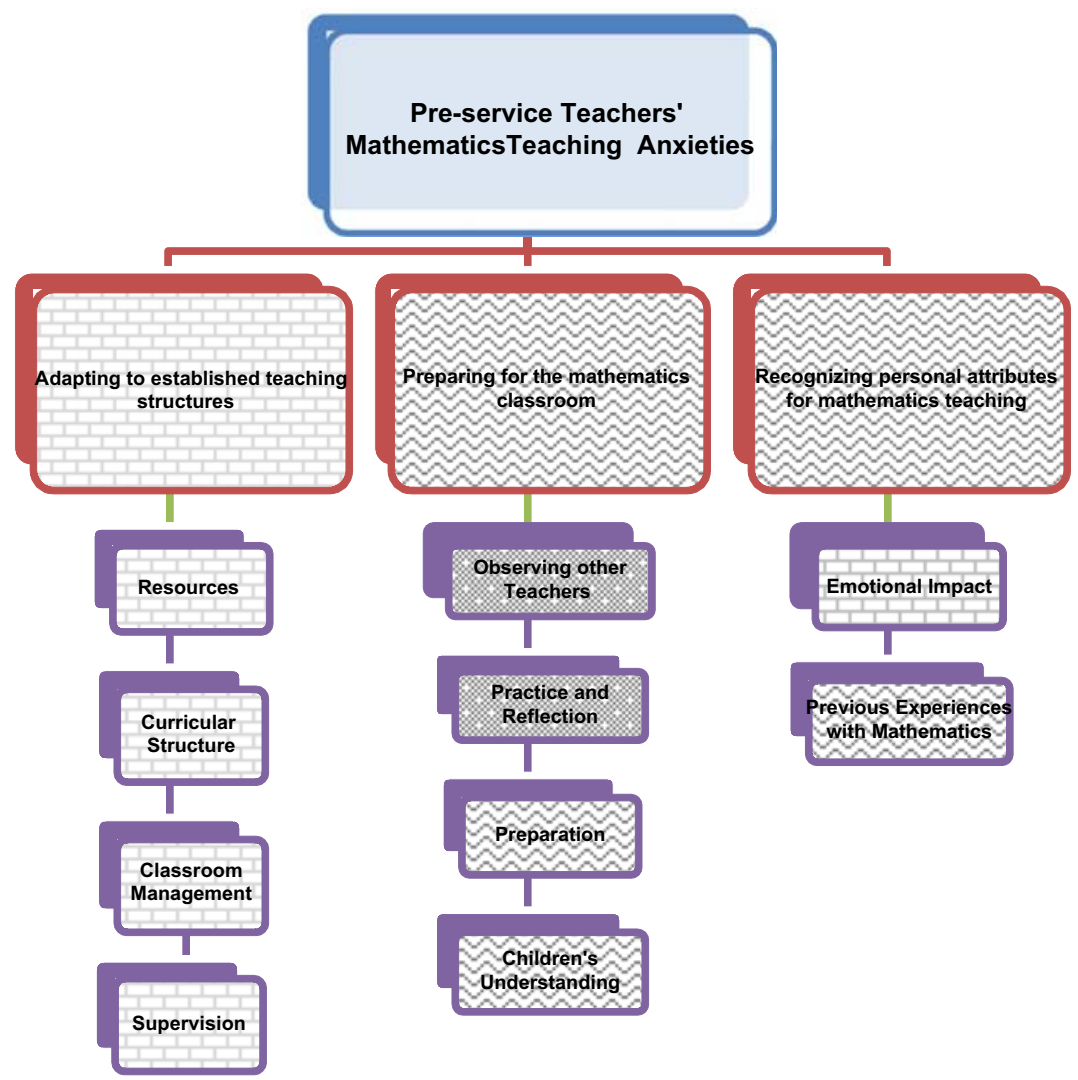

Figure 1. Categories and themes of pre-service teachers' mathematics teaching anxieties. Note: Brick background = categories and themes that increased anxieties; Dot background= themes that reduced anxieties; Zigzag background=categories and themes that sometimes increased, and other times reduced, anxieties.

\section{Themes: Adapting to established teaching structures}

Pre-service teachers' reflections indicated that some of their anxieties stemmed from the established teaching structures of the elementary classroom. Table 1 shows that 57 quotes were coded within this category, representing $29.1 \%$ of all pre-service teacher quotes. The themes included in this category reveal pre-service teachers' anxieties regarding: resources, the curriculum, classroom management practices, and the established structure for the supervision. These structures represent events within mathematics practice-teaching experiences that are outside of pre-service teachers' locus of control.

\section{Resources}

The first theme in the category of Adapting to established teaching structures focused on pre-service teachers' MTA concerning teaching resources in their practicum classrooms $(N=21 ; 36.8 \%)$. The following statements represent the spectrum of resources that increased pre-service teachers' anxieties for teaching mathematics 
in the elementary classroom, including the use of manipulatives, technology, and curriculum materials.

My intimidation came from not always knowing the best ways to use various manipulatives and differentiate my instruction to fit the needs of each child. (PT36)

It was very rough for me because I was trying to emulate my teacher's usage of technology and materials but [it] did not particularly turn out the way I had planned. (PT2)

My teacher for the first week only did worksheets with them. I didn't see them do any program or lessons. She then handed me the math program and said to teach for the rest of my time. (PT23)

These pre-service teachers' statements reveal how learning to use a variety of new resources in the teaching environment impacted their levels of anxiety for teaching mathematics.

\section{Curricular structure}

Pre-service teachers included statements in their reflections surrounding the theme of the curricular structure in the practicum classroom $(N=9 ; 15.8 \%)$. In some of the elementary classrooms in which the pre-service teachers were placed, teachers were using scripted programs for their schoolwide mathematics curriculum. Some pre-service teachers viewed the scripted program as something that lessened anxiety for teaching mathematics:

With having a book and lesson plan to follow, I was very confident in teaching these lessons. I knew what questions I was going to ask, when I was going to introduce new terms, and how I was going to assess throughout the lesson to know if the students understood me throughout the lesson. (PT1)

Other pre-service teachers wrote about how frustrating the scripted curriculum was for their mathematics teaching, noting that not using the script reduced their anxiety for teaching:

The best moment I had when teaching mathematics was when my practicum teacher allowed me to throw out the scripted lesson. This lesson was so much more engaging. This was the first day I truly enjoyed teaching math. (PT27)

Additionally, the data also revealed some interesting statements regarding developmental mathematics concepts within the mathematics curriculum, and how the curricular structure of the classroom impacted their anxiety for mathematics teaching:

At the beginning of my practicum, I lost a lot of confidence in any of my teaching skills, especially math. I think a lot of attributes to the fact that it is first grade, so it is a very basic math skills $[$ sic]. I never taught such basic skills, and that has been difficult. (PT39) 
As the pre-service teachers' statements within the theme of curricular structure reveal, there were strong and varied views about how classroom curriculum can impact anxiety for teaching mathematics.

\section{Classroom management}

Not surprisingly, the data included statements related to pre-service teachers' increased MTA when faced with classroom management issues in the elementary classroom $(N=13 ; 22.8 \%)$. These statements included anxiety regarding students' behavior in the classroom, as well as struggles with time management:

My afternoon kindergartners are very talkative as it is, but especially when they have a new teacher and a boring worksheet in front of them. This one was a particularly boring one and I had a hard time keeping their interest. (PT43)

The students did not want to listen to me, and just spoke Spanish to each other thinking that I couldn't understand. I wasn't able to get them to focus at all, and they learned absolutely nothing. I was so frustrated and kept looking at the clock for it to be over. (PT28)

I did not feel very confident when I taught my first math lesson because I was introducing a whole new topic and I was short on time. I did not know quite how to condense the lesson that I had prepared. (PT2)

These comments show how classroom structures and the elements of classroom management contributed to their pre-service teachers' anxieties for teaching mathematics. However, it should be noted that classroom management is a theme that would mostly likely generalize to other elementary disciplines as well.

\section{Supervision}

Another activity that is part of the established teaching structure is the relationship between the pre-service teacher, the supervising classroom teacher, and the university supervisor. The experience of having various supervisors evaluating their mathematics teaching contributed to many pre-service teachers' anxiety $(N=14$; $24.6 \%$ ), however, the experience of being supervised is a required element of most practicum experiences, and is applicable to other content areas beyond mathematics. The following three statements written by pre-service teachers exemplify their anxiety about being observed by the supervising classroom teacher and the university supervisor.

The first whole class lesson I taught I was being observed by my supervisor. That caused a few more nerves during my first lesson. (PT51)

I felt a little inadequate with my cooperating teacher there just because she has had 15 years of experience and I am new. (PT11)

I didn't like the looks Mrs. C [classroom teacher] and Mrs. R [university supervisor] were giving me as I was teaching the whole class lesson. I got embarrassed and just wanted to hide and cry because I had not met their expectations. (PT35) 
Feelings of anxiety stemming from being observed, or supervised, in the practicum classroom while teaching mathematics were shared by many pre-service teachers within the reflection responses.

\section{Themes: Preparing for the mathematics classroom}

Another major category that emerged from the pre-service teachers' reflections included themes surrounding pre-service teachers' Preparing for the mathematics classroom. As demonstrated in Table 1, there were 81 pre-service teacher quotes coded within this category, which represents $41.3 \%$ of the data. Some of the themes identified in this category were ones that decreased pre-service teachers' anxieties about teaching mathematics when they were able to have positive experiences (i.e. observing other teachers and practice and reflection). Other themes sometimes resulted in decreasing anxiety, but at other times increased pre-service teachers' anxiety for teaching mathematics (i.e. preparation and children's understanding). In regard to pre-service teachers' locus of control, this was the category that fell in the middle; the classroom for which they were preparing was out of their control, but at times they were able to take control of mathematics practice-teaching experiences through their own observations, preparation, reflection, etc.

\section{Observing other teachers}

The data revealed that some pre-service teachers were able to observe their practicum classroom teachers prior to their own mathematics teaching $(N=7 ; 8.1 \%)$. The following statements show how observing their teachers helped to lessen pre-service teachers' own anxieties about teaching mathematics:

Another reason why I am more comfortable teaching math is because the teacher allowed me to observe the students a lot to see where they were at, observe her (the teacher) and how and what she taught. (PT21)

Another reason I believe I felt more confident is because I had time to watch how the teacher taught her lessons earlier on in the practicum. I got to observe what seemed to work with the students and their math routine. (PT52)

I was able to take the first week and really observe my cooperating teacher and notice her strategies for handling the classroom, and I think that really helped me when it was my turn to teach a lesson. (PT28)

As these pre-service teachers' statements show, the simple task of observing mathematics lessons within the elementary classroom where the pre-service teachers were placed had the effect of reducing their anxiety for teaching mathematics.

\section{Practice and reflection}

Another theme that emerged from the data focused on practice and reflection $(N=21 ; 85.9 \%)$, which often led to reducing pre-service teachers' anxiety-related events for teaching mathematics in the elementary classroom. The pre-service teachers described how repeated practice of teaching mathematics gave them more confidence. They also described how, if a lesson did not go well the first time, but they 
had the opportunity to reflect and re-teach the lesson, that the final positive outcome decreased their mathematics teaching anxiety.

During my practicum I was given many opportunities to teach the math lessons. At the beginning of my practicum I was not very confident in my ability to teach math. By the end of my practicum I began feeling much better. I still feel that I have room to improve in teaching math, but I feel I have come a long way. (PT27)

So, I sent the students out to recess and revaluated how I needed to teach. I finally found a way that I thought would be really clear to the students. They came back in and I re-taught them. It then turned into my best moment because I suddenly saw all the little light bulbs turn on. (PT25)

The theme of practice and reflection was not present in every pre-service teacher's practicum experience. However, these quotes represent statements made by pre-service teachers who experienced reduced MTA after practicing mathematics teaching, or reflecting upon and improving upon previous mathematics lessons through reteaching.

\section{Preparation}

It was apparent from pre-service teachers' statements that they experienced increased anxiety when faced with a lack of preparation $(N=22 ; 27.2 \%)$. In some instances, the lack of preparation was the fault of the pre-service teacher him/herself, whereas other times they felt under-prepared due to ad hoc teaching suggested by the classroom teacher:

I didn't take the time [to] go through what I would say and specific questions I would ask, I was a fish out of water. I found myself praying for the lesson to be over. It seemed to last forever. (PT54)

This, too, was a spur of the moment lesson. The teacher gave me warning that I would be teaching only about an hour before the lesson. I had helped him plan the lesson and gather all the materials, but I did not plan out my directions and instructions ... It was bad because of my lack of confidence and my lack of explicit and clear directions. (PT14)

On the other hand, some pre-service teachers wrote how their preparedness reduced their anxieties for mathematics teaching.

I am more confident in my ability than I was before and I know that if I prepare and plan well for my math lessons that I can teach in a manner that my students will learn and understand math better than they did before. (PT2)

By the time I got in front of the class I was feeling VERY confident with my ability to teach the concepts, answer questions, and help the children to understand. I know this is a direct result of my preparation. I would not have been successful without it. (PT4)

The theme of preparation was one that had mixed results for pre-service teachers, depending on whether or not they took the time to be prepared or their supervising classroom teacher afforded them the opportunity to have the time to prepare. The 
reflections revealed that more preparation decreased pre-service teachers' anxiety for mathematics teaching, whereas a lack of preparation increased pre-service teachers' mathematics teaching anxieties.

\section{Children's understanding}

The practice-teaching experiences impacted these pre-service teachers' anxieties when it came to ensure that children understood the mathematics being taught $(N=31 ; 38.3 \%)$. Pre-service teachers experienced greater anxiety when they recognized huge differences in children's achievement levels and when they observed that the children did not understand mathematics concepts or were not learning the mathematics based on the pre-service teacher's instruction. In fact, when asked to describe their best and worst teaching moments within the Lesson Plans and Reflection Assignment, 62\% (34 out of 55) of pre-service teachers referred to student understanding as their best moment and 38\% (21 out of 55) described how a lack of student understanding led to their worst teaching moment. The following statements reveal some of the pre-service teachers' increased anxiety concerning children's mathematical understanding:

The other reason I was not completely comfortable teaching math was because of the huge gap in levels of understanding. Some students were way past the lesson I was teaching, while with others it was almost too hard. (PT27)

My students were really confused and the whole lesson felt like a flop. When I went over the assessment, only 5 students understood the objective. (PT29)

The worst moment is when you are trying to teach a topic and you can see that your students just are not getting it but you don't know what to do to help them. You feel helpless. (PT10)

However, other pre-service teachers wrote statements regarding feelings of decreased anxiety when students understood the mathematics, or had experienced a mathematics breakthrough on a concept.

They all got $100 \%$ on their math assignments. It made me feel so good for the struggling math students to feel smart and actually get math on their own. (PT8)

He proceeded to answer all of the questions without a problem. It was so great to see it just click in his brain! I think the best moments are when the students get it! It makes it all worth it! (PT10)

The theme of children's understanding is one that affected pre-service teachers' mathematics teaching anxieties in different ways. When students did understand, pre-service teachers felt a surge of confidence, but when students struggled with mathematics, this increased their anxiety for teaching mathematics.

\section{Themes: Recognizing personal attributes for mathematics teaching}

The pre-service teachers' reflections revealed that their practice teaching was impacted by Recognizing personal attributes for mathematics teaching in the elementary classroom. Table 1 reveals that 58 pre-service teacher quotes, or $29.6 \%$ 
of all quotes, were coded within this category. The themes within this category represent the most internal locus of control for pre-service teachers and are often closely tied to their prior mathematics experiences, including those that produced anxiety. The themes of emotional impact and previous experiences with mathematics emerged in this category.

\section{Emotional impact}

The reflections data revealed that pre-service teachers' mathematics teaching sometimes resulted in very intense emotions to certain situations in the practicum classroom $(N=12 ; 20.7 \%)$. The following examples demonstrate the emotional impact on the pre-service teachers.

The teacher jumped in and pointed out my mistake. I was happy that she did because I didn't want to get the students mixed up, but at the same time I was very embarrassed. (PT51)

I did it wrong, and then my mind went blank for a moment. Then I just said, "Oh, wait, let me try that again". I erased and redid the problem and took it slower the second time. I felt really stupid. (PT41)

I was so worried that I would make some huge mistake and ruin the kid's lives forever because they won't know how to do the math concepts that I am teaching them. (PT13)

It was revealed that pre-service teachers experienced strong emotions linked to MTA during the teaching of mathematics.

\section{Previous experiences with mathematics}

The pre-service teachers revealed information regarding their mathematics backgrounds and histories, and how these previous experiences impacted their levels of anxiety during practice mathematics teaching $(N=43 ; 74.1 \%)$. Some pre-service teachers expressed negative personal experiences in their own learning of mathematics and this impacted how they viewed teaching mathematics to children. The following quote shows one example of the experiences of this group of pre-service teachers:

I was unsure how to proceed with the lesson because I was not as confident in my own ability. From the time I was young, I have not felt confident of my ability in math. Oftentimes, as a young child I was afraid to answer the problems incorrectly and as a future teacher I did want to teach my students incorrectly. (PT2)

Some pre-service teachers expressed that they themselves understood the mathematics concepts but that it was difficult for them to teach the mathematics to their students, as in the following two comments:

I was always really good at math growing up so I think that may be why I have a hard time teaching it. I can only think of the way I know how to do these problems and when students don't understand, I have a hard time coming up with another way to say it. I also get frustrated easily because [I] always got it and sometimes I don't understand how they DON'T get it. (PT7) 
A math concept may be easy for me to do, but to try and teach it is extremely hard for me. I don't always have the "big picture" of a certain concept, making it hard to teach that concept. (PT41)

There were other pre-service teachers who had difficult personal experiences in learning mathematics, but these difficulties served as an impetus for them to use a variety of instructional methods so that they could help every child to learn mathematics. As the following pre-service teacher's quote demonstrates, she sought out various instructional methods as a way to reach all of her students.

I feel like all of this [math struggles in the past] has actually served a purpose for me. Instead of expecting kids to just understand the way I explain, I more than anyone, understand that importance of teaching using different methods. (PT4)

As the statements related to pre-service teachers' previous experiences with mathematics show, there is a varied spectrum of how both positive and negative previous experiences can have different impacts on pre-service teachers' mathematics teaching anxiety.

\section{Discussion and implications}

The purpose of this study was to examine pre-service teachers' practicum-based mathematics classroom teaching experiences that contributed to their anxiety, or reduced their anxiety, during the teaching of elementary mathematics. The analysis of pre-service teachers' reflections on those experiences revealed that locus of control played an integral part in increasing vs. decreasing mathematics teaching anxiety. Locus of control refers to people's beliefs about whether the outcomes of their actions are contingent upon what they do (internal), vs. beliefs that outcomes are beyond their personal control (external) (Neill, 2006). As the results of this study reveal, events that increased or decreased pre-service teachers' MTA did not always align with the pre-service teachers' mathematics ability or history (Brown et al., 2011). Therefore, analyzing increases or decreases in MTA through the lens of locus of control provided one perspective for interpreting the results and providing suggestions for teachers of mathematics education methods courses.

\section{Teaching experiences that increased mathematics teaching anxiety}

All four of the themes in the category of Adapting to established teaching structures (resources, curricular structure, classroom management, and supervision) increased pre-service teachers' mathematics teaching anxiety. These four themes represented the most external locus of control for pre-service teachers. Additionally, in the broader category of Recognizing personal attributes for mathematics teaching, the theme emotional impact also increased anxiety (see Figure 1). What is common among these themes is that pre-service teachers had little or no control over them, or they perceived that they had little or no control over them. For example, the classroom teachers' reliance on worksheets and the scripted mathematics curriculum increased MTA because pre-service teachers may have perceived that teaching mathematics lessons was beyond their control, and in the hands of the classroom teacher. Similarly, when pre-service teachers were required to teach 
scripted mathematics lessons where they had little control over the pacing and content, they described their increased anxiety when classroom management issues emerged.

\section{Implications for mathematics educators}

Research has shown that even when pre-service teachers demonstrate meaningful strides toward reform-based mathematics strategies in their university coursework, these benefits can be reversed after they spend time in traditional, lecture-based mathematics classrooms (Ebby, 2000). This issue is a difficult one; university placement coordinators do not always have the flexibility of placing pre-service teachers in elementary classrooms that are consistent with reform-based mathematics teaching practices. In order to address the resources, curricular structure, and classroom management of elementary classrooms, one worthwhile university experience could include pre-service teachers researching and finding examples of mathematics textbooks and lessons that are in their local schools, and reporting back to the university class. Then, pre-service teachers may feel a more internal locus of control for the variety of established classroom structures they will face. Many mathematics educators are already using university course time to discuss classroom management issues that are specific to mathematics (for example, the use of manipulatives or calculators), which can provide pre-service teachers more internal locus of control over the various classroom environments they will face.

When pre-service teachers recognized disparity between what was occurring in the elementary classroom compared with the reform-based mathematics they learned in university courses, the task of planning and executing mathematics lessons to please both the classroom teacher and the university supervisor increased anxiety. While universities cannot remove this anxious experience, perhaps better communication can provide a clearer picture of what pre-service teachers can expect during these observation periods to make the experience less anxious. One strategy for addressing this issue is to invite supervisors to visit the methods course and explain their observation methods and their expectations to pre-service teachers; supervisors could be invited to lead a discussion forum within the methods course technology supplemental platform (Blackboard, Angel, etc.).

Some pre-service teachers internalized moments from their mathematics teaching in very emotional and personal ways when they stated that they felt "stupid" or "dumb" if they made a mistake while teaching. These reflection comments were guided by an external locus of control. Pre-service teachers were embarrassed when the cooperating teacher noticed an error, or when a university supervisor observed a lesson that went poorly. Although the emotions were internal, the anxiety was increased by being watched, judged, or embarrassed by an external person. It is interesting to hypothesize whether or not these types of emotions can be predicted, changed, or validated. While some experiences are, in fact, out of the pre-service teachers' control (external), other experiences will rely on what the pre-service teacher does in the teaching situation (internal). Helping pre-service teachers to develop an understanding of the importance of recognizing when outcomes are contingent upon their own actions may improve their sense of confidence for teaching. Mathematics educators can incorporate discussions and role-playing that prepare pre-service teachers with decision-making strategies to handle these emotionally anxious moments. The National Council of Teachers of Mathematics published a 
list of suggestions for pre-service teachers that include strategies related to emotional issues; one suggestion is to remove the presence of ego in mathematics classrooms, while another is to emphasize that everyone makes occasional mistakes when doing mathematics (Stuart, 2000). Discussing emotions and practicing decision-making skills based on scenarios using the categories in Figure 1 prior to pre-service teachers' practicum experiences could inhibit some of their anxious emotional reactions.

In summary, the established teaching structures that caused increased MTA for pre-service teachers (resources; curricular structure; classroom management; supervision; and emotional impact), all shared an external locus of control, which left preservice teachers feeling a lack of self-agency and self-determination (Neill, 2006).

\section{Teaching experiences that both increased/decreased mathematics teaching anxiety}

The categories of Preparing for the mathematics classroom and Recognizing personal attributes for mathematics teaching included themes that sometimes increased and other times decreased pre-service teachers' mathematics teaching anxiety. The themes within these two categories that represent this bidirectional impact on preservice teachers include: preparation, children's understanding, and previous experiences with mathematics (see Figure 1). Once again, by analyzing the results through the lens of the impact of locus of control, there are commonalities across the category themes. Across the themes of preparation, children's understanding, and previous experiences with mathematics, pre-service teachers' anxieties were decreased when they felt more internal locus of control regarding their mathematics teaching. When teaching experiences in these same themes were perceived to be beyond pre-service teachers' control (external), this increased their mathematics teaching anxiety.

\section{Implications for mathematics educators}

Preparation increased pre-service teachers' anxiety when they were not prepared, but decreased anxiety when they were well prepared. Pre-service teachers wrote about moments of feeling anxious when they were asked to teach something on the spot and did not have time to adequately prepare, which is consistent with an external locus of control. Other pre-service teachers shared how their extra preparation time paid off in their teaching, which is consistent with an internal locus of control and decreased their anxiety for teaching mathematics. It is significant that pre-service teachers learn early on the importance of being prepared when teaching mathematics. In addition, university supervisors should indicate to supervising classroom teachers the impact that teaching without preparation can have on the anxiety of the pre-service teacher, hopefully discouraging "impromptu" teaching situations. The theme of preparation also has some implications for possible course materials development. For example, a short video clip or role-playing scenario introducing this situation could be used to prompt a "What would you do in this situation?" discussion with pre-service teachers, which could positively impact an internal locus of control when faced with an impromptu teaching situation in the elementary classroom.

Children's understanding influenced increases and decreases in pre-service teachers' anxiety. While some pre-service teachers viewed their mathematics teaching 
success with children as contingent upon their own actions and planning (internal), others experienced anxiety when children's learning seemed to be beyond their control (external). Almost $40 \%$ of the pre-service teachers described their worst teaching moment to be when students were confused and not able to understand (external), whereas $60 \%$ described their best teaching moment to be when students, especially struggling students, grasped a concept (internal). These findings support making diagnosis of students' misconceptions and error patterns a more significant part of mathematics methods experiences. Pre-service teachers can practice identifying misconceptions, learn questioning strategies for clarifying student thinking, and learn to identify both beneficial and harmful levels of cognitive conflict and confusion. Through explicitly modeling examples of these kinds of lesson adjustments within mathematics methods courses, the potential for anxiety-related mathematics teaching events could be decreased, hence providing a more internal locus of control for pre-service teachers' mathematics teaching.

Previous experiences with mathematics also affected pre-service teachers' reflection statements and their perceived locus of control in different ways. Based on previous research on pre-service teachers and mathematics anxiety, we expected that pre-service teachers who had negative previous experiences with mathematics would also have more negative reflections regarding their elementary mathematics teaching, and vice versa for those who had positive mathematics backgrounds. These previous experiences were evident when pre-service teachers wrote statements such as, "I was never very good at math," or "Math always came easily to me." However, positive and negative prior experiences did not always match preservice teachers' reflections on their actual practicum teaching experiences. For example, several pre-service teachers described how their negative mathematics histories were an impetus for teaching mathematics better to their future students; this represents an individual recognizing a weakness and taking an internal locus of control in order to overcome it. On the other hand, some pre-service teachers who reported positive mathematics backgrounds wrote statements indicating their concern over having to take a mathematics concept and break it down to the subconcepts and terms so that an elementary student could understand. For these pre-service teachers, knowing their mathematics content was not enough to provide them an internal locus of control for teaching mathematics to children. Pre-service teacher vignettes, based on previous mathematics practice teaching, could be useful for future pre-service teachers in mathematics methods courses. Analyzing prior pre-service teachers' reflections, who experienced anxiety-related events or an external locus of control for different reasons, could reduce the potential for anxiety. The results of the present study reveal that the assumption that pre-service teachers with negative mathematics background experiences will also have negative teaching experiences, and that those with positive mathematics background experiences will have positive teaching experiences, may not always be valid. This is an area that warrants further investigation.

The three themes that resulted in mixed impacts for pre-service teachers' mathematics teaching anxieties (preparation, children's understanding, and previous experiences with mathematics) had interesting connections to locus of control, as well as connections to mathematics content knowledge. Pre-service teachers who described negative previous experiences with mathematics were able to recognize this deficit, and take internal control over their preparation and their commitment to children's understanding of mathematics. As mathematics educators become aware 
of the potential impact of these themes for increasing or decreasing pre-service teachers' mathematics teaching anxieties, they can better design mathematics methods courses, activities, and discussions to prepare pre-service teachers for a lower anxiety teaching experience.

\section{Conclusion}

The concept of mathematics anxiety has been studied for decades, and has often been utilized to broadly paint elementary pre-service teachers into two categories: those that have high mathematics anxiety and will therefore be poor mathematics teachers vs. those that have low levels of mathematics anxiety and therefore have the potential to be effective mathematics teachers. The findings of this study challenge this generalized, traditional view of the relationship between mathematics anxiety and elementary pre-service teachers. With the more recent introduction of the MTA construct (Brown et al., 2011; Peker, 2009), a more fluid and multidirectional relationship between elementary pre-service teachers' levels of mathematics anxiety, specific classroom teaching experiences, and locus of control provides new perspectives through which to address pre-service teachers' early mathematics teaching.

Much prior research has focused on mathematics anxiety experienced by preservice teachers, while less attention has been given to the construct of mathematics teaching anxiety. A pre-service teachers' current level of mathematic anxiety is a result of past experiences, while a pre-service teachers' mathematics teaching experiences (and, perhaps, their mathematics teaching anxiety) are in the future. To address mathematics anxiety in pre-service teachers, mathematics methods courses often focus on attempting to reduce the mathematics anxiety of pre-service teachers in the hopes that this will influence the mathematics teaching experiences (and, perhaps, their mathematics teaching anxiety) that are in the pre-service teachers' future. We assert that this focus is looking backward at pre-service teachers' prior experiences in an attempt to minimize the impact that the past negative experiences will have on the pre-service teachers' future teaching.

We propose that mathematics methods courses for pre-service teachers' need to take a more forward-looking stance. A forward-looking stance would focus on preservice teachers developing the strategies they need to take on a more internal locus of control in the face of potentially anxiety-producing experiences. In a more forward-looking approach, pre-service teachers' background experiences take on less focus. The reason we propose that pre-service teachers' background experiences take on less focus is that, as our results indicated, whether past experiences have been negative or positive, pre-service teachers' mathematics teaching experiences can be positive, depending on a variety of factors that occur during the practiceteaching experiences. A more forward-looking stance means that mathematics methods courses must include practice in strategies that address the potentially anxietyproducing experiences, both those that are out of the pre-service teachers' control (e.g. supervision) and those that are within the pre-service teachers' control (e.g. preparation).

Experience has shown that placing the emphasis on minimizing pre-service teachers' negative mathematics experiences from the past, in the hopes of ensuring that pre-service teachers will have positive future mathematics teaching experiences, is not enough. Mathematics methods courses need a shift in thinking that looks 
forward to the pre-service teachers' future mathematics teaching. This future time perspective approach has been studied widely in the field of psychology and is tied to self-regulation (McInerney, 2004). A more forward looking approach toward future teaching experiences would be to use the categories outlined in Figure 1 to develop scenarios or role-playing situations that expose pre-service teachers to the potentially anxiety-producing events that may occur in typical elementary classroom. These types of opportunities allow pre-service teachers to think about what they will do and say in these types of situations, promoting their own self-regulatory behaviors and giving them some measure of internal control over the complexity of the typical classroom. Simulating a potentially anxiety-producing situation through role-play in the safe environment of the mathematics methods course allows the pre-service teacher to enact possible strategies before actually being in that situation in front of a supervisor, classroom teacher, or a group of 25 fourthgrade students. Looking forward and developing strategies for various situations allows pre-service teachers to think through ways to self-regulate their behavior and take a more internal locus of control in situations, subsequently resulting in more positive and effective instructional strategies and experiences in preparation for teaching mathematics in their own classrooms.

\section{References}

Beilock, S.L., Gunderson, E.A., Ramirez, G., \& Levine, S. (2010). Female teachers' math anxiety impacts girls' math achievement. Retrieved from http://lucian.uchicago.edu/ workshops/education/files/2010/01/TeacherAnxiety_PNAS.pdf Published online before print January 25, 2010, doi: 10.1073/pnas.0910967107 PNAS February 2, 2010. 107(5), 1.

Brady, P., \& Bowd, A. (2005). Mathematics anxiety, prior experience and confidence to teach mathematics among pre-service education students. Teachers and Teaching: Theory and Practice, 11(1), 37-46.

Brown, A.B., Westenskow, A., \& Moyer-Pakenham, P.S. (2011). Elementary pre-service teachers: Can they experience mathematics teaching anxiety without having mathematics anxiety? Issues in the Undergraduate Mathematics Preparation of School Teachers: The Journal, 5, 1-14.

Bursal, M., \& Paznokas, L. (2006). Mathematics anxiety and preservice elementary teachers' confidence to teach mathematics and science. School Science and Mathematics, 106(4), $173-180$.

Cady, J., \& Rearden, K. (2007). Pre-service teachers' beliefs about knowledge, mathematics, and science. School Science and Mathematics, 107(6), 237-245.

Dogan-Dunlap, H., Dunlap, J., Izquierdo, E., \& Kosheleva, O. (2007). Learn by teaching: A mediating approach to teaching and learning mathematics for prospective teachers. Issues in the Undergraduate Mathematics Preparation of school Teachers 4, (Curriculum), April, 2007 (www.k-12prep.math.ttu.edu).

Ebby, C.B. (2000). Learning to teach mathematics differently: The interaction between coursework and fieldwork for preservice teachers. Journal of Mathematics Teacher Education, 3(1), 69-97.

Gresham, G. (2004). Mathematics anxiety in elementary students. CMC ComMuniCator, 29 (2), 28-29.

Gresham, G. (2007). A study of mathematics anxiety in pre-service teachers. Early Childhood Education Journal, 35(2), 181-188.

Harper, N.W., \& Daane, C.J. (1998). Causes and reduction of math anxiety in preservice elementary teachers. Action in Teacher Education, 19(4), 29-38.

Hembree, R. (1990). The nature, effects, and relief of mathematics anxiety. Journal of Research in Mathematics Education, 21, 33-46. 
Levine, G. (1993). Prior mathematics history, anticipated mathematics teaching style, and anxiety for teaching mathematics among pre-service elementary school teachers. Proceeding of the fifteenth annual meeting of the North American chapter of the International Groups for the Psychology of Mathematics Education, Assisi, 2, 26.

McInerney, D.M. (2004). A discussion of future time perspective. Educational Psychology Review, 16(2), 141-151.

Neill, J. (2006). What is locus of control? Retrieved from http://wilderdom.com/psychology/ loc/LocusOfControlWhatIs.html

Peker, M. (2009). Pre-service teachers' teaching anxiety about mathematics and their learning styles. Eurasia Journal of Mathematics, Science, \& Technology Education, 5(4), 335-345.

Richardson, F., \& Suinn, R. (1972). The mathematics anxiety rating scale: Psychometric data. Journal of Counseling Psychology, 19, 551-554.

Rose, J.S., \& Medway, F.J. (1981). Teacher locus of control, teacher behavior and student behavior as determinants of student achievement. Journal of Educational Research, 74, $246-258$.

Rotter, J.B. (1966). Generalized expectancies for internal versus external control of reinforcement. Psychological Monographs, 80(Whole No. 609).

Stake, R.E. (1995). The art of case study research. Thousand Oaks, CA: Sage.

Strauss, A.L., \& Corbin, J. (1998). Basics of qualitative research: Techniques and procedures for developing grounded theory (2nd ed.). Thousand Oaks, CA: Sage.

Stuart, V.B. (2000). Math curse or Math anxiety? Teaching Children Mathematics, 6(5), $330-335$.

Tobias, S. (1978). Overcoming mathematics anxiety. New York, NY: W.W. Norton.

Trujillo, K.M., \& Hadfield, O.D. (1999). Tracing the roots of mathematics anxiety through in-depth interviews with preservice elementary teachings. College Student Journal, 33 (2), 219-232.

Uusimaki, L., \& Nason, R. (2004). Causes underlying pre-service teachers' negative beliefs and anxieties about mathematics. Proceedings of the 26th Conference of the International Group for the Psychology of Mathematics Education, Norwich, 4, 369-376.

Vinson, B.M. (2001). A comparison of preservice teachers' mathematics anxiety before and after a methods class emphasizing manipulatives. Early Childhood Education Journal, 29(2), 89-94.

Vinson, B.M., Haynes, J., Brasher, J., Sloan, T., \& Gresham, R. (1997). A comparison of preservice teachers' mathematics anxiety before and after a methods class emphasizing manipulatives (ERIC Document Reproduction Service No. ED 417136). 